\title{
Efficacy of Needle Thoracostomy following Iatrogenic Pneumothorax in Critically Ill Patients
}

\author{
Collin Sprenker ${ }^{1 *}$, Francis Dillon ${ }^{1}$, Prachiti H Dalvi ${ }^{1}$, Devanand Mangar ${ }^{2}$, and Enrico Camporesi ${ }^{2}$ \\ ${ }^{1}$ Team Health Anesthesia, USA \\ ${ }^{2}$ University of South Florida \& TEAM Health Anesthesia, USA
}

Submission: March 17, 2017; Published: April 06, 2017

*Corresponding author: Enrico M Camporesi, Tampa General Circle, Suite A327 Tampa, FL 33606 Email: ecampore@health.usf.edu

\begin{abstract}
We report a series of 3 patients who experienced iatrogenic pneumothoraces in the ICU: these were resolved with a single needle thoracostomy and no patients experienced recurrence. The following criteria were used to determine whether needle thoracostomy was appropriate: all pneumothoraces were unilateral and greater than $30 \%$ apical in location; patients did not have effusion, hemothorax, purulence, or other drainage; coagulation and platelet parameters in range; no history of surgeries on the hemithorax; and patient consent was obtained prior to the procedure. A needle thoracostomy can be an appropriate, less invasive alternative to chest tube insertion to resolve post-operative pneumothoraces.
\end{abstract}

Keywords: Resolution of iatrogenic pneumothorax; Needle thoracostomy; Critical care medicine

\section{Introduction}

Due to increased invasive monitoring and treatment modalities in critically ill patients, iatrogenic pneumothorax occurs with an incidence rate of 4-15\% [1], greater amongst teaching facilities [2]. Not accounting for asymptomatic or occult occurrences [3] raises the expected overall incidence of pneumothorax. Traditional treatment for spontaneous or iatrogenic pneumothorax is surgical thoracostomy (chest) tube insertion. Despite being widely accepted, this practice is not without complications and results in significant pain as well as increased morbidity and mortality [4]. Herein we report 3 cases in which an iatrogenic pneumothorax in a critically ill patient was resolved via a single bedside needle thoracostomy. Each patient provided written consent to participate in this research study and for the publication of their information as a clinical case report.

There has recently been interest in treating spontaneous pneumothorax with needle thoracostomy with success, however this has not gained widespread favor amongst intensivists. Several randomized controlled studies have demonstrated the efficacy of needle aspiration as comparable to chest tube insertion for the treatment of primary spontaneous pneumothorax [5-7]. Despite these reports, few literature accounts have described the efficacy of needle aspiration for iatrogenic pneumothorax in critically ill patients.

\section{Case Report}

This was a retrospective review of patient's medical charts. The patients gave written informed consent for the procedure and for release of information for educational purposes. The following criteria were used to determine whether needle thoracostomy was the appropriate intervention: unilateral and greater than or equal to $30 \%$, apical in location, and patients were not expected to have effusion, hemothorax, purulence, or other drainage, and coagulation and platelet parameters in adequate range, no history of surgeries on the hemithorax, and signed informed consent for the procedure.

\section{Procedure description}

All procedures were performed by a single anesthesiologist at the bedside in the intensive care unit. Following collection of informed consent for the procedure, patients were prepped and draped in sterile fashion. Analgesia was achieved with 50-75 mcg of IV fentanyl and local anesthesia was accomplished with Ropivacaine $.5 \%$ or lidocaine $1 \%$. The rib inter space between the third and fourth ribs were accessed by inserting a 16 or 18 gauge needle on the ipsilateral side of the pneumothorax with gentle downward force until contact was made with the third rib anteriorly, along the midclavicular line. The angiocatheter was directed superiorly until located in the avascular soft tissue of the inter costal space. The needle was then directed downward 
an additional $2 \mathrm{~cm}$ until air was aspirated. The catheter was then threaded off and a thumb seal was made on the catheter hub. A stopcock was attached immediately to prevent further air entry. A 60 cc syringe was attached to the stopcock and air was slowly

Table 1: Patient Demographics and Pneumothorax Descriptions.

\begin{tabular}{|c|c|c|c|c|c|c|c|c|}
\hline $\begin{array}{l}\text { Patient } \\
\text { Number }\end{array}$ & $\begin{array}{c}\text { Age/ } \\
\text { Gender }\end{array}$ & $\begin{array}{l}\text { Iatrogenic or } \\
\text { Spontaneous }\end{array}$ & $\begin{array}{l}\text { Location/ } \\
\text { Size }\end{array}$ & $\begin{array}{l}\text { Hemodynamic } \\
\text { or Respiratory } \\
\text { Compromise? }\end{array}$ & $\begin{array}{l}\text { MediaStinal } \\
\text { Shift? }\end{array}$ & $\begin{array}{l}\text { Mode of } \\
\text { Ventilation }\end{array}$ & $\begin{array}{c}\text { Air Removed } \\
\text { (L) }\end{array}$ & $\begin{array}{c}\text { Days to } \\
\text { Resolution } \\
\text { (Confirmed } \\
\text { by Chest } \\
\text { X-Ray) }\end{array}$ \\
\hline 1 & $39 / \mathrm{M}$ & $\begin{array}{l}\text { Iatrogenic post-op } \\
\text { retropleural thoracic } \\
\text { spine surgery }\end{array}$ & Large left & No & No & $\begin{array}{c}\text { Low flow } \\
\text { nasal cannula }\end{array}$ & $1.32 \mathrm{~L}$ & 2 \\
\hline 2 & $58 / \mathrm{F}$ & $\begin{array}{l}\text { Iatrogenic s/p right } \\
\text { internal jugular } \\
\text { central venous access }\end{array}$ & Large right & No & Yes & $\begin{array}{c}\text { Low flow } \\
\text { nasal cannula }\end{array}$ & $1.4 \mathrm{~L}$ & 0 \\
\hline 3 & $43 / F$ & $\begin{array}{c}\text { Iatrogenic s/p } \\
\text { parathyroidectomy }\end{array}$ & $\begin{array}{l}\text { Large right } \\
\text { apical } \\
50 \%\end{array}$ & No & No & $\begin{array}{l}\text { Low flow } \\
\text { Nasal canula }\end{array}$ & $.6 \mathrm{~L}$ & 1 \\
\hline
\end{tabular}

Immediately as the catheter was withdrawn an occlusive dressing (Tegaderm) was applied and reinforced until this was seen to be airtight by the provider. Daily follow up chest x-ray were obtained to confirm resolution of pneumothorax (Figure 1).

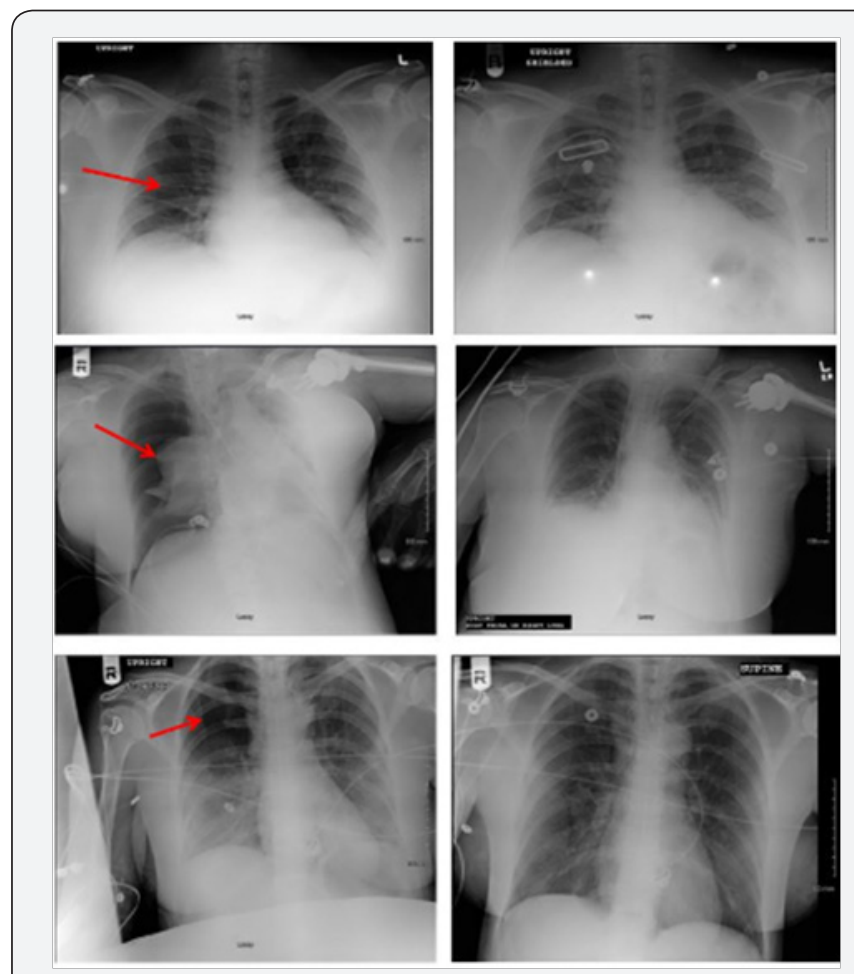

Figure 1: Resolved pneumothoraces in 3 patient's post-needle thoracostomies. The tip of the arrow highlights pulmonary shadow on an anterior-posterior chest x-ray.

All pneumothoraces were iatrogenic in nature, identified by plain chest $\mathrm{x}$-ray and radio graphically resolved following a single needle thoracostomy. No patients experienced recurrence, complications, or required subsequent chest tube insertion. An withdrawn by $60 \mathrm{cc}$ aliquots (released into ambient air) and recorded (final volume in Table 1). When resistance was felt and no further air could be withdrawn, the catheter was withdrawn while the stopcock remained in the "off position". average of $1.11 \mathrm{~L}$ of air was removed (range $0.6-1.4 \mathrm{~L}$ ). Average day to resolution was 1.25 days with a range of $0-2$ days. All three patients were on low flow nasal cannula.

\section{Discussion}

Chest tube insertion is currently the standard of care for mechanically ventilated patients [8]. In this case series we have demonstrated 3 patients that had iatrogenic pneumothoraces resolved following a single needle thoracostomy. In this small case series we have demonstrated complete resolution of pneumothorax without chest tube insertion. The decision not to place a chest tube in mechanically ventilated patients is up to clinician discretion and may have a high failure rate. Further investigations with a larger sample size are required before conclusions can be made.

Idris and Hefny described needle thoracostomy in a 63 year old male with a $>30 \%$ pneumothorax to his left hemithorax following a fall to his chest [9]. In this case report the patient deferred placement of a chest tube and conservative treatment was provided. He was monitored with serial imaging studies which revealed slight reduction in size of the pneumothorax. He was discharged on hospital day 6 and a CT chest on 3 month follow up revealed complete resolution of the pneumothorax.

Kulvatunyou et al. described their experience with 14 French pigtail catheters for traumatic pneumothorax compared to chest tube insertion [10]. A retrospective analysis revealed a comparable efficacy in comparison to chest tubes. There was a greater occurrence of tube failure rate in the pigtail catheter group compared to the chest tube group, however statistical significance was not established.

A 2006 randomized controlled trial compared simple aspiration vs. chest tube insertion for spontaneous pneumothorax in 137 patients [5]. Re-occurrences of pneumothorax in the aspiration group were greater, however 
not statistically significant. Complications and analgesia requirements were greater in the chest tube group, but also not statistically significant. Overall, efficacy was comparable between the methods. The authors concluded that needle aspiration is an alternative method to chest tube insertion as the initial treatment for the first episode of primary spontaneous pneumothorax.

Our experience suggests that needle thoracostomies are an appropriate alternative to tube thoracostomy to resolve apical uncomplicated iatrogenic pneumothoraces. We believe current guideline for routine tube thoracostomies may need to be revised however clinical judgment, experience and patient stability will guide treatment modality in all cases. We continue to recommend chest tube insertion for patients with tension pneumothorax resulting in hemodynamic instability. This case series attempts to expand indications of needle thoracostomy to iatrogenic etiology and patients on mechanical ventilation. A randomized controlled study with outcomes focused on ICU stay, days to resolution, cost and complications are required to confirm the widespread use of this technique.

\section{Author Roles}

CS contributed to data collection, data analysis, and manuscript writing. FD contributed to data collection, data analysis, and manuscript revisions. PD contributed to maintaining regulatory documentation, data analysis, and manuscript writing. DM was involved with data analysis and manuscript revisions. EC was involved in data collection, data analysis, regulatory documentation, and manuscript writing.

\section{References}

1. Strange C (1999) Pleural complications in the intensive care unit. Clin Chest Med 20(2): 317 - 327.

2. John J, Seifi A (2016) Incidence of iatrogenic pneumothorax in the United States in teaching vs. non-teaching hospitals from 2000 to 2012. J Crit Care 34: 66-68.

3. Omar HR, Abdelmalak H, Mangar D, Rashad R, Helal E, et al. (2010) Occult pneumothorax, revisited. J Trauma Manaq Outcomes 4: 12.

4. Kwiatt M, Tarbox A, Seamon MJ, Swaroop M, Cipolla J, et al. Thoracostomy tubes: A comprehensive review of complications and related topics. Int J Crit Illn Inj Sci 4(2): 143-155.

5. Ayed AK, Chandrasekaran C, Sukumar M (2006) Aspiration versus tube drainage in primary spontaneous pneumothorax: a randomised study. Eur Respir J 27(3): 477-482.

6. Aguinagalde B, Zabaleta J, Fuentes M, Bazterargui N, Hernández C, et al. (2010) Percutaneous aspiration versus tube drainage for spontaneous pneumothorax: systematic review and meta-analysis. Eur J Cardiothorac Surg 37(5): 1129-1135.

7. Parlak M, Uil SM, van den Berg JW (2012) A prospective, randomised trial of pneumothorax therapy: manual aspiration versus conventional chest tube drainage. Respir Med 6(11): 1600-1605.

8. Gilbert TB, McGrath BJ, Soberman M (1993) Chest tubes: indications, placement, management, and complications. J Intensive Care Med 8(2): 73-86.

9. Idris BM, Hefny AF (2016) Large pneumothorax in blunt chest trauma: Is a chest drain always necessary in stable patients? A case report. ] Surg Case Rep 24: 88-90.

10. Kulvatunyou N, Vijayasekaran A, Hansen A, Wynne JL, O'Keeffe T, et al. (2011) Two-year experience of using pigtail catheters to treat traumatic pneumothorax: a changing trend. J Trauma 71(5): 11041107.

Your next submission with Juniper Publishers will reach you the below assets

- Quality Editorial service

- Swift Peer Review

- Reprints availability

- E-prints Service

- Manuscript Podcast for convenient understanding

- Global attainment for your research

- Manuscript accessibility in different formats ( Pdf, E-pub, Full Text, Audio)

- Unceasing customer service

Track the below URL for one-step submission https://juniperpublishers.com/online-submission.php 